Editorial

\title{
EUJAPA as an open access journal
}

\author{
Kwok Ng ${ }^{1,2}$
}

Published: $1^{\text {st }}$ May 2019

From when the European Journal of Adapted Physical Activity (EUJAPA) began publishing scholarly articles, it was always through an open access mechanism. Open access means that the scientific papers are free to access to anyone without extra costs. The Budapest Open Access initiative was formed in 2002 (BOAI, 2002) and stressed research can be accelerated through open access. Moreover, science needs to be available to all, irrespective of being rich or poor so everyone can access the same information. Thus, through open access the enlargement of the readership through open access to science there can be more humanity throughout understanding through intellectual debates. To achieve this, BOAI published two strategies; 1. publishing through self-archiving (the authors store articles in open electronic archives) and 2. publishing through open access journals. These strategies are commonly known as Green Open Access (self-archiving) and Gold Open Access (published through the journal). EUJAPA is a Gold Open Access journal, whereby the readers have rights to read, download, copy, distribute, print, search, or link to the full texts of these articles under the Creative Commons Attribution (CC BY) license.

Over 15 years later since the initiative met, even the European Commission has embraced the philosophy of the BOAI, by stipulating that science that comes from projects funded by the European Commission, such as Horizon 2020 must be published in a way that is openly accessible (Schiltz, 2018). Yet, only two countries in Europe (Switzerland and United Kingdom) have over half their publications that are openly accessible (European Commission, 2019). One of the main drawbacks to open access publishing is the cost associated with publishing. Many of the publishers who provide open access options do so by charging the authors to pay for the costs. To cover the cost for publishers, authors may be asked to pay an article submission charge, so that the authors pay for it to be reviewed, or asked to pay an article processing charge, which would pay for the processing of a manuscript through to publication. In some cases, publishers charge both.

EUJAPA is run by volunteers, hence there are no article submission or processing charges despite being a Gold Open Access journal. One way that was identified to reduce the costs, is to ask the authors to be compliant with the templates used for submission and publishing. To date, just under half of the submissions did not follow these instructions and were deleted from the system immediately. It is important that authors can help the editors as much as possible so that publishing in this journal continues to be free and without the need of bringing a paid person to carry out the tasks from submission to publication.

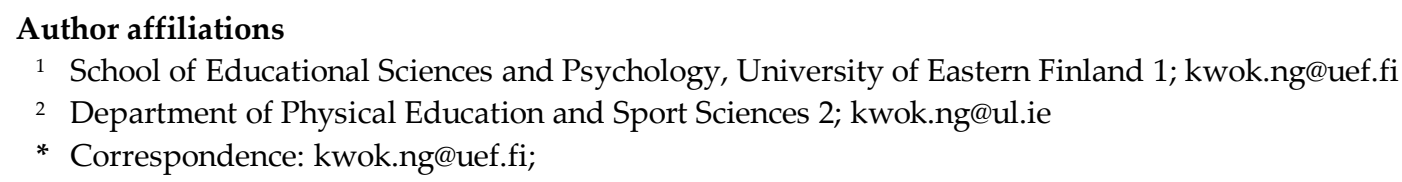

\section{References}

BOAI. (2002). Read the Budapest Open Access Initiative. Retrieved from http://bit.ly/BOAIeu European Commission. (2019). Trends for open access to publications. Retrieved from http://bit.ly/trendOA Schiltz M. (2018) Science Without Publication Paywalls: cOAlition S for the Realisation of Full and Immediate Open Access. PLoS Med 15(9): e1002663. doi:10.1371/journal.pmed.1002663

(C) 2019 by the authors. Submitted for possible open access publication under the terms and conditions of the Creative Commons Attribution (CC BY) license (http://creativecommons.org/licenses/by/4.0/). 